\title{
Consumo e digestibilidade de dietas contendo feno de jitirana para ovinos em terminação
}

\section{Intake and digestibility of diets containing jitirana hay for finishing sheep}

\author{
Daniel Cézar da Silva ${ }^{1}$, Desirée Coelho de Mello Seal ${ }^{2}$, Francisco Jocélio Cavalcante Souza ${ }^{2}$, Ariádne de Barros Carvalho ${ }^{2}$, \\ Ana Valéria Mello de Souza Marques ${ }^{1}$
}

Resumo: A jitirana é encontrada em abundância na região semiárida do Nordeste brasileiro, conferindo durante o período chuvoso elevada produção de fitomassa e satisfatório teor de nutrientes, o que a credencia como alimento alternativo para ruminantes. Dessa forma, avaliou-se o efeito da substituição de 0; 25; 50 e 75\% do feno de capim-tifton 85 pelo feno de jitirana (FJ) sobre o consumo e digestibilidade em dietas para ovinos, distribuídos em delineamento de quadrado latino 4 x 4 duplo, com oito ovinos. $\mathrm{O}$ consumo de matéria seca $(\mathrm{CMS})$ e nutrientes foram influenciados $(\mathrm{P}<0,05)$ pela inclusão do FJ à dieta, com exceção do consumo fibra em detergente neutro (CFDN) em g por animal por dia, com média 682,76 $\pm 125,13$. O CMS elevou-se linearmente $(\mathrm{P}<0,05)$ em $6,33 \mathrm{~g}$ por unidade percentual do $\mathrm{FJ}$ acrescido. Houve efeito linear positivo $(\mathrm{P}<0,05)$ para consumo de proteína bruta (CPB) e CFDN, com elevação de $1,11 \mathrm{~g}$ por animal por dia e $0,02 \%$ do peso corporal, respectivamente, por unidade percentual de FJ incluso. Houve efeito positivo na digestibilidade da fibra em detergente neutro (DFDN) que resultou em elevação linear $(\mathrm{P}<0,05)$ de $0,14 \%$. O FJ em substituição ao feno de capim-tifton 85 eleva o consumo de matéria seca (MS) e nutrientes, mas não influencia a digestibilidade destes, a exceção da DFDN, com recomendação de uso para $75 \%$ de substituição, por permitir atendimento às exigências nutricionais quanto à ingestão de MS, proteína bruta (PB), e elevar a DFDN.

Palavras-chave: Forrageira nativa; Merremia aegyptia; Valor nutritivo; Semiárido.

\begin{abstract}
Jitirana is found in semiarid region of brazilian northeastern, giving high biomass production and satisfactory nutrient content during the rain season that qualifies as alternative feed for ruminants. Thus, it was evaluated the substitution effect of $0 ; 25 ; 50$ and $75 \%$ of tifton 85 hay to jitirana hay $(\mathrm{JH})$ on intake and digestibility of diets for sheep, randomized in double 4 x 4 latin square design, with eight sheep. Dry matter $(\mathrm{DM})$ and nutrients intake were influenced $(\mathrm{P}<.05)$ by $\mathrm{JH}$ inclusion, except for neutral detergent fiber (NDF) intake, that was around $682.76 \pm 125.13 \mathrm{~g}$ per animal per day. DM intake increased linearly $(\mathrm{P}<.05)$ raising approximately $6.33 \mathrm{~g}$ per unit percentage of $\mathrm{JH}$ increased. There was positive linear effect $(\mathrm{P}<.05)$ for crude protein $(\mathrm{CP})$ end NDF intake, with an increase of $1.11 \mathrm{~g}$ per animal per day and $0.02 \%$ of body weight, per unit percentage of JH included. There was a positive effect for NDF digestibility which resulted in linear increase $(\mathrm{P}<.05)$ by $0.14 \%$. JH in substitution of tifton 85 hay increases DM and nutrients intake, but does not influence the digestibility, except for NDF digestibility, recommending use of $75 \%$ in substitution, which allows satisfactory nutritional requirements for DM and CP intake, and increase the NDF digestibility.
\end{abstract}

Key-words: Native forage; Merremia aegyptia; Nutritional value; Semiarid.

\footnotetext{
*Autor para correspondência

Recebido para publicação em 13/09/2016; aprovado em 02/01/2017

${ }^{1}$ Docentes do Instituto Federal de Educação, Ciência e Tecnologia da Paraíba, Rua Pedro Antunes, s/n, São Gonçalo, CEP: 58.814-000, Paraíba, Brasil, daniel.cezar@ifpb.edu.br ; anavaleriavet@hotmail.com

${ }^{2}$ Discentes do Curso de Medicina Veterinária do Instituto Federal de Educação, Ciência e Tecnologia da Paraíba, Rua Pedro Antunes, s/n, São Gonçalo, CEP: 58.814-000, Paraíba, Brasil, desiree.seal@hotmail.com, francisco.jocelio@hotmail.com, carvalhoariadne@hotmail.com
} 


\section{INTRODUÇÃO}

A produção de ovinos e caprinos no Nordeste brasileiro vem crescendo significativamente nos últimos anos, sendo caracterizada como importante atividade comercial e social para os produtores locais. Especificamente para a Ovinocultura, verifica-se na referida região efetivo de $11.156,79$ ovinos, o que representa $60,6 \%$ do efetivo nacional (IBGE, 2015). Estes dados confirmam a potencialidade desta produção pecuária para essa região, sobretudo para o semiárido, onde são exploradas raças rústicas, bem adaptadas ao clima tropical.

Apesar deste efetivo representativo, os índices de desfrute do rebanho ovino na referida região são considerados insatisfatórios, com maiores comprometimentos durante os períodos de escassez de chuvas. De acordo com Linhares et al. (2005), a irregular distribuição de chuvas promove considerável variação na produção anual quantitativa e qualitativa de forragens, o que condiciona inadequado consumo de matéria seca e nutrientes, comprometendo a produção animal.

A escassez de alimento forrageiro promove ainda considerável elevação dos custos de produção, visto que os produtores são obrigados a investir em concentrados comerciais para suprir a deficiência de nutrientes limitantes.

O cenário apresentado orienta para a necessidade de adoção de estratégias nutricionais viáveis e adaptáveis às condições semiáridas do Nordeste, com destaque para a conservação de forragem na forma de feno. Aguiar et al. (2006) comentam que o processo de fenação constitui alternativa ao problema da sazonalidade de forragem, permitindo que o excedente produzido em pastagens, nativas ou cultivadas, possa ser armazenado e empregado na alimentação dos animais em períodos de restrição alimentar.

A adaptação da referida técnica para as regiões semiáridas nordestinas consiste na escolha de forrageiras não utilizadas convencionalmente para fenação, tais como as forrageiras nativas, por apresentarem produtividade satisfatória, ciclo de produção resistente ao período de estiagem, aceitação pelos animais em pastejo e baixo custo de produção em comparação às pastagens cultivadas.

Dentre estas forrageiras ressalta-se a jitirana (Merremia aegyptia L. Urban), planta leguminosa nativa da região Nordeste, que se prolifera durante o período chuvoso, quando confere elevada produção de fitomassa e satisfatório teor de nutrientes. Pertencente à família das convolvuláceas, esta forrageira possui suculência e odor agradável, o que permite ótima aceitação por ruminantes, fazendo parte de sua dieta sempre que encontrada em condições de pastejo.

Segundo Linhares et al. (2010), esta forrageira eleva a produção de fitomassa à medida que o estádio fenológico se prolonga com produção máxima de $32.600 \mathrm{~kg} \mathrm{ha}^{-1}$ aos 112 dias de rebrota, apresentando teor de proteína bruta satisfatório com concentrações de 31,0 e $17,2 \%$ na matéria seca aos 15 e 120 dias de idade fenológica, respectivamente, o que admite o atendimento das exigências mínimas deste nutriente para animais ruminantes.

Por se tratar de forrageira não convencional para alimentação de ovinos, tornam-se necessárias as avaliações dos aspectos do consumo e digestibilidade da matéria seca e nutrientes que são determinantes para o satisfatório desempenho animal. Dessa forma, objetivou-se avaliar o consumo e digestibilidade de dietas contendo feno de jitirana (Merremia aegyptia L. Urban) para ovinos em terminação.

\section{MATERIAL E MÉTODOS}

O experimento foi conduzido no setor de Ovinocultura do Instituto Federal da Paraíba (IFPB), Unidade São Gonçalo, em Sousa-PB, situado em latitude $06^{\circ} 50^{\prime} 22^{\prime}$ Sul, longitude $38^{\circ} 17^{` 42}$ " Oeste, a 220 metros de altitude. O clima é semiárido, quente, do tipo Bsh, segundo a classificação de Köpper-Geiger (PEEL et al., 2007) com precipitação anual média de $654 \mathrm{~mm}$, concentradas no período de janeiro a junho. A temperatura média anual é de $27{ }^{\circ} \mathrm{C}$, com máxima de $38{ }^{\circ} \mathrm{C}$, e umidade relativa média de $64 \%$. A vegetação predominante da região é a caatinga hiperxerófila.

Avaliou-se o consumo e a digestibilidade in vivo de dietas totais para ovinos em terminação, contendo níveis de 0 ; 25; 50 e 75\% de feno de jitirana (Merremia aegyptia L. Urban), em substituição ao volumoso com base na matéria seca. As dietas possuíram relação volumoso/concentrado 70:30, utilizando-se como volumoso o feno de capim-tifton 85 (Cynodon spp.), proveniente de área adubada, colhido aos 30 dias de rebrota. O concentrado foi composto por milho em grão desintegrado, farelo de soja, sendo o núcleo vitamínicomineral incorporado ao concentrado (Tabela 1). As dietas foram isoenergéticas e isoproteicas (Tabela 2), formuladas segundo as exigências nutricionais preconizadas pelo NRC (2007), para atender ganho médio diário de $200 \mathrm{~g}$.

Tabela 1. Composição centesimal e bromatológica das dietas contendo feno de jitirana em substituição ao feno de capim-tifton 85

\begin{tabular}{|c|c|c|c|c|}
\hline \multirow{3}{*}{ Ingrediente/Nutriente } & \multicolumn{4}{|c|}{ Nível substituição do feno de capim-tifton $85\left(\mathrm{~g} \mathrm{~kg}^{-1}\right)$} \\
\hline & 0 & 25 & 50 & 75 \\
\hline & \multicolumn{4}{|c|}{ Composição centesimal } \\
\hline Feno de capim-tifton 85 & 62,48 & 46,75 & 31,15 & 15,56 \\
\hline Feno de jitirana & 0,0 & 15,65 & 31,29 & 46,90 \\
\hline Milho & 25,30 & 27,05 & 28,56 & 30,19 \\
\hline Farelo de soja & 8,04 & 6,38 & 4,84 & 3,18 \\
\hline \multirow[t]{2}{*}{ Mistura mineral } & 4,18 & 4,17 & 4,17 & 4,17 \\
\hline & \multicolumn{4}{|c|}{ Composição bromatológica } \\
\hline \multirow[t]{2}{*}{ Matéria seca (MS), \% } & 89,81 & 88,69 & 89,47 & 89,13 \\
\hline & \multicolumn{4}{|c|}{$\%$ na $M S$} \\
\hline Matéria mineral & 9,88 & 9,07 & 11,90 & 11,49 \\
\hline Proteína bruta & 10,81 & 11,02 & 12,76 & 13,28 \\
\hline Fibra em detergente neutro & 63,57 & 62,53 & 61,54 & 59,90 \\
\hline
\end{tabular}


Tabela 2. Composição bromatológica dos ingredientes das dietas experimentais

\begin{tabular}{lcccc} 
& \multicolumn{5}{c}{ Ingrediente } \\
\cline { 2 - 5 } Nutriente & Feno de jitirana & $\begin{array}{c}\text { Feno } \\
\text { de } \\
\text { capim- } \\
\text { tifton }\end{array}$ & $\begin{array}{c}\text { Farelo } \\
\text { de } \\
\text { soja }\end{array}$ & Milho em grão desintegrado \\
\hline Matéria seca (\%) & 88,31 & 90,10 & 83,07 & $\%$ na MS \\
Cinza & 7,86 & 6,72 & 6,32 & 1,55 \\
Proteína bruta & 14,02 & 7,95 & 49,14 & 9,36 \\
Fibra em detergente neutro & 67,28 & 78,08 & 23,68 & 15,23 \\
\hline
\end{tabular}

Foram utilizados oito ovinos mestiços Santa Inês $\mathrm{x}$ Dorper, machos não castrados, com peso corporal médio inicial de $17 \pm 3,5 \mathrm{~kg}$, idade de sete meses, em bom estado sanitário e nutricional, que foram confinados individualmente em galpão com piso cimentado recoberto por maravalha, com acesso às dietas experimentais fornecidas diariamente às $8 \mathrm{~h}$ e $16 \mathrm{~h}$, de forma a proporcionar sobra de $15 \%$ em relação ao consumo do dia anterior, além do fornecimento de água ad libitum.

Ao início do período experimental, os animais foram pesados em jejum para posterior distribuição nos tratamentos, segundo delineamento de quadrado latino 4 x 4 duplo simultâneo, com quatro tratamentos (dietas) e oito repetições (ovinos), adotando-se a variação do peso corporal ao início do período experimental para distribuição dos animais nos quadrados.

O período experimental teve duração de 55 dias, sendo 15 para adaptação às condições experimentais e o restante subdivididos em quatro períodos de 10 dias, dos quais sete foram destinados à adaptação ao período e os três dias seguintes à coleta de dados.

Para a determinação do consumo, adotou-se o método de coleta total das sobras, que foram quantificadas antes de cada refeição, retirando-se alíquotas de $20 \%$, em seguida acondicionadas em sacos plásticos devidamente identificados e congelados em freezer $\left(-5 \mathrm{a}-10^{\circ} \mathrm{C}\right)$.

Ao final do período de coletas, as amostras de sobras foram degeladas, homogeneizadas e formadas amostras compostas por animal. O consumo diário de matéria seca e nutrientes foi estimado pela diferença entre a dieta oferecida e as sobras, sendo expresso em gramas por animal por dia e porcentagem do peso corporal (\%PC).

As fezes foram obtidas pelo método de coleta total in vivo, sendo realizadas com auxílio de bolsas coletoras colocadas na região posterior dos animais. Foi registrada a produção total de fezes, com retirada de alíquota de $20 \%$ que foram armazenadas em sacos plásticos, identificadas e congeladas em freezer $\left(-5 \mathrm{a}-10^{\circ} \mathrm{C}\right)$ para posteriores análises. Ao final dos períodos de coletas, as fezes foram degeladas e homogeneizadas, formando amostras compostas de sobras e fezes por animal.

Os coeficientes de digestibilidade aparente $(\mathrm{CD} \%)$ da matéria seca (MS), matéria orgânica (MO), proteína bruta (PB), e fibra em detergente neutro (FDN) foram calculados pela diferença entre o nutriente ingerido e o excretado nas fezes, sendo utilizada a fórmula: $\mathrm{CD} \%=[($ nutriente ingerido - nutriente nas fezes)/nutriente ingerido] x 100 .
As análises das amostras de dietas experimentais, sobras e fezes foram realizadas no Laboratório de Análise FísicoQuímica do IFPB, Campus Sousa, Unidade São Gonçalo, onde foram pré-secas a $55^{\circ} \mathrm{C}$ em estufa com circulação forçada de ar por $72 \mathrm{~h}$, moídas em moinho tipo Willey com peneira de malha com crivos $1 \mathrm{~mm}$, e submetidas à determinação dos teores de matéria seca (MS), e com base na MS, matéria mineral (MM), proteína bruta $(\mathrm{PB})$ e fibra em detergente neutro (FDN) segundo metodologias descritas por (GOMES; OLIVEIRA, 2011). Os teores de matéria orgânica (MO) foram determinados pela fórmula: $\mathrm{MO} \%$ da $\mathrm{MS}=100$ $\% \mathrm{MM}$.

Para avaliação do consumo e digestibilidade da matéria seca e nutrientes adotou-se o modelo matemático: $\hat{\mathrm{Y}}_{\mathrm{ijklm}}=\mu+$ $\alpha_{\mathrm{i}}+\beta_{\mathrm{j}}+\gamma_{\mathrm{k}}+\delta_{\mathrm{l}}+\alpha \delta_{\mathrm{m}}+\varepsilon_{\mathrm{ijklm}}$, sendo $\hat{\mathrm{Y}}_{\mathrm{ijklm}}=$ valor da variável obtida em cada observação; $\mu=$ média geral do parâmetro; $\alpha_{\mathrm{i}}$ $=$ efeito do quadrado latino $i$, sendo $i=1,2 ; \beta_{\mathrm{j}}=$ efeito do período $j$, sendo $j=1,2,3$ e $4 ; \gamma_{\mathrm{k}}=$ efeito do animal $k$, sendo $k=1,2,3$ e $4 ; \delta_{1}=$ efeito do tratamento $l$, sendo $l=1,2,3$ e $4 ; \alpha \delta_{\mathrm{m}}=$ efeito da interação quadrado latino $i \mathrm{x}$ tratamento $\delta$; $\varepsilon_{\mathrm{ijklm}}=$ erro associado a cada observação.

Os dados foram analisados segundo o procedimento PROC MEANS do logiciário estatístico SAS (2001), com realização de estatísticas descritivas para média, desviopadrão e coeficiente de variação. Foram realizadas ainda análises de regressão linear e quadrática por meio do PROC GLM, segundo método de quadrados mínimos, adotando-se para a seleção dos modelos a significância de 0,05 , bem como o coeficiente de regressão dos mesmos. As análises de correlação foram realizadas segundo procedimento PROC CORR, adotando-se o nível de significância de 0,05.

\section{RESULTADOS E DISCUSSÃO}

O consumo de matéria seca (CMS) e nutrientes foram influenciados $(\mathrm{P}<0,05)$ pela inclusão do feno de jitirana à dieta, com exceção do consumo de matéria orgânica (CMO) e fibra em detergente neutro (CFDN) em g por animal por dia, em média 1032,05 \pm 390,24 e 682,76 \pm 125,13, respectivamente (Tabela 3). O CMS apresentou elevação linear $(\mathrm{P}<0,05)$ de $6,33 \mathrm{~g}$ por unidade percentual do feno de jitirana acrescido à dieta (Tabela 3), e os valores obtidos para este parâmetro, em todos os níveis de substituição, atenderam às exigências nutricionais para CMS estabelecidas pelo NRC (2007) para categoria de animal empregado nesta pesquisa, de $760 \mathrm{~g}$ de MS por animal por dia. 
Tabela 3. Médias e equações de regressão para consumo de matéria seca e nutrientes em ovinos mestiços alimentados com dietas contendo feno de jitirana (FJ)

\begin{tabular}{|c|c|c|c|c|c|c|c|}
\hline & \multicolumn{4}{|c|}{ Feno de jitirana (FJ \%) } & \multirow{2}{*}{$\begin{array}{c}\text { Média } \pm \\
\text { desvio }\end{array}$} & \multirow{2}{*}{$\mathrm{R}^{2}$} & \multirow{2}{*}{$\mathrm{CV}(\%)$} \\
\hline & 0 & 25 & 50 & 75 & & & \\
\hline & \multicolumn{4}{|c|}{ Consumo de matéria seca } & & & \\
\hline g por animal por dia & 827,79 & 1184,15 & 1214,30 & 1345,62 & $1 *^{\mathrm{a}}$ & 0,40 & 14,83 \\
\hline$\% \mathrm{PC}$ & 3,80 & 4,68 & 5,07 & 6,51 & $2 *$ & 0,44 & 13,64 \\
\hline \multirow[b]{2}{*}{ g por animal por dia } & \multicolumn{4}{|c|}{ Consumo de matéria orgânica } & \multirow{3}{*}{$\begin{array}{l}1032,05 \pm \\
390,24, \mathrm{~ns}^{\mathrm{b}} \\
3^{*}\end{array}$} & \multirow[b]{2}{*}{-} & \multirow[b]{2}{*}{15,21} \\
\hline & 743,63 & 1075,75 & 1064,17 & 1208,60 & & & \\
\hline \multirow[t]{2}{*}{$\% \mathrm{PC}$} & 3,42 & 4,25 & 4,45 & 5,84 & & 0,44 & 13,99 \\
\hline & \multicolumn{4}{|c|}{ Consumo de proteína bruta } & \multirow{3}{*}{$\begin{array}{l}4^{*} \\
5 *\end{array}$} & \multirow{3}{*}{$\begin{array}{l}0,49 \\
0,47\end{array}$} & \multirow{3}{*}{$\begin{array}{l}14,19 \\
14,06\end{array}$} \\
\hline \multirow{2}{*}{$\begin{array}{l}\text { g por animal por dia } \\
\% \mathrm{PC}\end{array}$} & 92,46 & 137,41 & 161,77 & 177,01 & & & \\
\hline & 0,42 & 0,54 & 0,68 & 0,86 & & & \\
\hline \multirow[b]{2}{*}{ g por animal por dia } & & de fibra & letergent & itro & \multirow{3}{*}{$\begin{array}{c}682,76 \pm \\
125,13, \mathrm{~ns} \\
6^{*}\end{array}$} & \multirow[b]{2}{*}{-} & \multirow[b]{2}{*}{15,82} \\
\hline & 504,77 & 713,79 & 714,24 & 798,25 & & & \\
\hline$\% \mathrm{PC}$ & 2,58 & 2,81 & 2,97 & 3,85 & & 0,47 & 12,04 \\
\hline \multicolumn{3}{|c|}{$\begin{array}{l}{ }^{\mathrm{a}} *=\mathrm{P}<0,05 ;{ }^{\mathrm{b}} \mathrm{ns}=\text { não significativo. } \\
{ }^{1} \hat{\mathrm{Y}}=905,42+6,3346 \mathrm{FJ} \\
{ }^{2} \hat{\mathrm{Y}}=3,7323+0,0342 \mathrm{FJ}\end{array}$} & ${ }^{4} \hat{Y} \hat{Y}$ & $\begin{array}{l}3663+0, \\
0,2278+ \\
4093+0\end{array}$ & ${ }^{6} \hat{\mathrm{Y}}=$ & $\overline{00+0}$ & $4 \mathrm{FJ}$ \\
\hline
\end{tabular}

O CMS é considerado parâmetro determinante para o desempenho animal, uma vez que todos os nutrientes estão

inseridos na matéria seca. Resende et al. (2008) reforçam que o consumo voluntário máximo é determinado pela combinação do potencial animal por demanda de energia e capacidade física do trato digestório, sendo estes influenciados pelo estado fisiológico do animal, composição da dieta, qualidade e quantidade do alimento oferecido, além de poder ser reduzido por doenças ou por estresse.

Neste sentido, a participação de $75 \%$ de feno de jitirana na composição da dieta proporcionou incremento de $62,6 \%$ para o CMS em g por animal por dia em relação aos animais alimentados com dieta contendo $0 \%$ de feno de jitirana, o que reforça as vantagens da utilização desta forrageira nativa na alimentação de ovinos, por não apresentar comprometimento do primeiro parâmetro do desempenho animal que é o CMS.

A avaliação do CMS deve ser realizada em conjunto ao teor de fibra em detergente neutro (FDN) das dietas, visto que o conteúdo de FDN dos alimentos representa importante parâmetro para avaliação destes, uma vez que esta entidade nutricional apresenta grande influência sobre os mecanismos reguladores do consumo em animais ruminantes (MACEDO JÚNIOR et al., 2006).

De acordo com Cruz et al. (2010), alimentos com teor de FDN acima de $60 \%$ podem levar a menor CMS devido à limitação física do rúmen. Entretanto, os resultados obtidos nesta pesquisa demonstram que o teor de FDN não constituiu fator limitante ao CMS, o que é provavelmente atribuído ao fato do feno de jitirana apresentar menor teor deste constituinte $(67,28 \%$ de FDN na MS) em relação ao feno de capim-tifton $85(78,08 \%$ de FDN na MS) (Tabela 2), ocasionando redução dos teores totais de FDN nas dietas, quando da inclusão do feno de jitirana.

Apesar da ausência de efeito $(\mathrm{P}>0,05)$ para o consumo de matéria orgânica em g por animal por dia, o consumo de matéria orgânica expresso em \%PC, apresentou efeito linear positivo $(\mathrm{P}<0,05)$, com elevação de $0,030 \% \mathrm{PC}$ por unidade percentual do feno de jitirana acrescido à dieta, acompanhando a tendência verificada para o consumo de matéria seca em \%PC (Tabela 3).
Houve efeito linear positivo $(\mathrm{P}<0,05)$ para consumo de proteína bruta (CPB) com elevação de $1,11 \mathrm{~g}$ por animal por dia e $0,006 \%$ PC por unidade percentual do feno de jitirana acrescido à dieta (Tabela 3), o que satisfez às exigências nutricionais para CPB estabelecidas pelo NRC (2007), de 0,093 g de PB por animal por dia.

A elevação no CPB é possivelmente explicada pelo maior teor deste nutriente no feno de jitirana (14,02\% na MS) em relação ao feno de capim-tifton 85 (7,95\% na MS) (Tabela 1), o que associado à elevação no consumo de matéria seca e matéria orgânica como verificado anteriormente (Tabela 3), condicionou maior ingestão deste constituinte, resultando em reais benefícios ao desempenho animal.

$\mathrm{O}$ consumo de fibra em detergente neutro (CFDN) em $\% \mathrm{PC}$ resultou em efeito linear positivo $(\mathrm{P}<0,05)$ com elevação de $0,016 \%$ do PC por unidade percentual de feno de jitirana acrescido à dieta (Tabela 3). Em média, o CFDN em $\%$ PC foi de 3,05 \pm 0,56, o que segundo Macedo Júnior et al. (2006) pode ser considerado elevado para animais ruminantes.

O teor médio de FDN nas dieta, 61,88\% na MS, com $43,32 \%$ (Tabela 2), proveniente do ingrediente volumoso, denotam adequação às condições mínimas fermentativas no ambiente ruminal no que se refere à necessidade de fibra. Os teores de FDN das dietas experimentais podem ser considerados elevados, entretanto estes não comprometeram os parâmetros de consumo de $\mathrm{MS}$ e $\mathrm{MO}$, ao contrario do verificado por Cardoso et al. (2006) em que a elevação dos níveis de FDN das dietas comprometeu a ingestão de MS e nutrientes.

Não houve efeito $(\mathrm{P}>0,05)$ da inclusão do feno de jitirana às dietas sobre a digestibilidade da matéria seca (DMS) e digestibilidade da proteína bruta (DPB) com médias $67,84 \pm 2,40$ e $69,41 \pm 1,63 \%$, respectivamente (Tabela 4), fato considerado benéfico, uma vez que todos os coeficientes estão acima do limite de $60 \%$, para dietas com satisfatório valor nutritivo. 
Tabela 4. Médias e equações de regressão para digestibilidade aparente da matéria seca (DMS\%), da matéria orgânica (DMO\%), proteína bruta (DPB\%) e fibra em detergente neutro (DFDN\%) em ovinos mestiços alimentados com dietas contendo feno de jitirana (FJ)

\begin{tabular}{|c|c|c|c|c|c|c|c|}
\hline & \multicolumn{4}{|c|}{ Feno de jitirana (FJ \%) } & \multirow{2}{*}{ Média \pm desvio } & \multirow{2}{*}{$\mathrm{R}^{2}$} & \multirow{2}{*}{$\mathrm{CV}(\%)$} \\
\hline & 0 & 25 & 50 & 75 & & & \\
\hline DMS\% & 64,79 & 67,34 & 67,82 & 70,65 & $67,84 \pm 2,40, \mathrm{~ns}^{\mathrm{a}}$ & - & 14,21 \\
\hline $\mathrm{DMO} \%$ & 68,54 & 71,44 & 70,59 & 74,08 & $71,33 \pm 9,312, \mathrm{~ns}$ & - & 13,47 \\
\hline DPB\% & 69,19 & 67,35 & 70,09 & 71,21 & $69,41 \pm 1,63, \mathrm{~ns}$ & - & 13,42 \\
\hline DFDN\% & 61,49 & 66,75 & 68,21 & 72,64 & $1 * \mathrm{~b}$ & 0,42 & 14,76 \\
\hline
\end{tabular}

${ }^{\mathrm{a}} \mathrm{ns}=$ não significativo; ${ }^{\mathrm{b}} * \mathrm{P}<0,05$.

${ }^{1} \hat{\mathrm{Y}}=62,1557+0,1374 \mathrm{FJ}$

A inclusão do feno de jitirana não influenciou $(\mathrm{P}>0,05)$ a digestibilidade da matéria orgânica (DMO) com média $71,33 \pm 9,31 \%$ (Tabela 4). A DMO apresenta relação com o conteúdo de energia dos alimentos com possibilidade de ser utilizada como estimador do valor energético de dietas. Nesta situação, ao levar em consideração o consumo de matéria orgânica de 1032,05 g por animal por dia (Tabela 3) associada à respectiva digestibilidade (Tabela 4) obteve-se $736,14 \mathrm{~g}$ de matéria orgânica digestível, o que equivale a $772,95 \mathrm{~g}$ de nutrientes digestíveis totais (NDT) e 3,4 Mcal de energia digestível disponíveis para os animais. O teor de NDT estimado nesta pesquisa supera em $54,59 \%$ a exigência de $500,00 \mathrm{~g}$ de NDT, estabelecida pelo NRC (2007) para o perfil de animais desta investigação.

Estes resultados corroboram com depoimentos de pequenos produtores de que o consumo de jitirana por animais ruminantes é comumente associado à elevação de produtividade, sobretudo na produção de leite por caprinos, ovinos e bovinos. Verifica-se nesta situação, que a referida forrageira mesmo apresentando considerável fração fibrosa possui atributos que a credenciam como forrageira alternativa para rebanhos inseridos no semiárido.

Houve efeito linear positivo $(\mathrm{P}<0,05)$ para digestibilidade da fibra em detergente neutro (DFDN) com elevação de $0,14 \%$, por unidade percentual do feno de jitirana acrescido à dieta (Tabela 4).

Nesta pesquisa, a elevação na DFDN justifica ainda a elevação no CMS, fato confirmado pela correlação positiva $\left(r^{2}=0,78, P<0,01\right)$ entre estes parâmetros, com este resultado possivelmente atribuído à maior degradação ruminal da FDN oriunda do feno de jitirana em comparação ao feno de capimtifton 85 com possibilidade de elevação na taxa de esvaziamento ruminal e consequentemente elevando o CMS.

Mertens (2009) confirma estes resultados ao enfatizar que o consumo e a digestibilidade da FDN são parâmetros interligados, com substancial impacto sobre o desempenho de animais ruminantes, uma vez que a FDN representa a fração dos alimentos com lenta taxa de degradação ruminal. Em adição, a elevada heterogeneidade química e física entre a FDN dos diversos alimentos condiciona diferentes resultados em relação ao consumo e digestibilidade dos nutrientes, havendo necessidade de constantes avaliações, sobretudo ao se trabalhar com alimentos alternativos para animais ruminantes.

Os valores para digestibilidade da FDN registrados nesta investigação estiverem acima dos verificados por Jalali et al. (2012), 55\% DFDN, ao avaliarem o desempenho de ovinos alimentados com restolho cultural como alimento alternativo para animais ruminantes. Levando-se em consideração os coeficientes de digestibilidade médio da FDN em todos os níveis de feno de jitirana em substituição ao volumoso, verifica-se que estes estiveram acima dos $60 \%$, considerado limiar para dietas com satisfatório valor nutritivo, denotando que o uso do feno de jitirana não comprometeu o parâmetro de digestibilidade da FDN.

\section{CONCLUSÃO}

O feno de jitirana em dietas para ovinos em terminação eleva o consumo de matéria seca (MS) e nutrientes, mas não influencia a digestibilidade aparente destes, com exceção da digestibilidade da fibra em detergente neutro (FDN), sendo recomendado o uso de $75 \%$ de feno de jitirana em substituição ao feno de capim-tifton 85, por permitir atendimento às exigências nutricionais quanto à ingestão de MS e elevar a digestibilidade da FDN.

\section{REFERÊNCIAS}

AGUIAR, E. M.; LIMA, G. F. C.; SANTOS, M. V. F.; CARVALHO, F. F. R.; GUIM, A.; MEDEIROS, H. R.; BORGES, A. Q. Rendimento e composição químicobromatológica de fenos triturados de gramíneas tropicais. Revista Brasileira de Zootecnia, Viçosa-MG, v.35, n.6, p.2226-2233, 2006.

CARDOSO, A. R.; PIRES, C. C.; CARVALHO, S.; GALVANI, D. B.; JOCHIMS, F.; HASTEMPFLUG, M.; WOMMER, T. P. Consumo de nutrientes e desempenho de cordeiros alimentados com dietas que contêm diferentes níveis de fibra em detergente neutro. Ciência Rural, Santa Maria, v.36, n.1, p.215-221, 2006.

CRUZ, B. C. C.; SANTOS-CRUZ, C, L.; PIRES, A. J. V.; ROCHA, J. B.; SANTOS, S. B.; BASTOS, M. P. V. Composição bromatológica da silagem de capim-elefante com diferentes proporções de casca desidratada de maracujá (Passiflora edulis Sims f. flavicarpa). Revista Brasileira de Ciências Agrárias, Recife, v.5, n.3, p.434-440, 2010.

GOMES, J. C.; OLIVEIRA, G. F. Análises físico-químicas de alimentos. Viçosa-MG: Editora da UFV, 2011. 303p.

IBGE. INSTITUTO BRASILEIRO DE GEOGRAFIA E ESTATÍSTICA Pesquisa Pecuária Municipal, v.43, p.1-47, 2015. Disponível em: < http://biblioteca.ibge.gov.br/visualizacao/periodicos/84/ppm_ 2015_v43_br.pdf>. Acesso em: 22 de fev. 2017.

JALALI, A. R.; NØRGAARD, P.; WEISBJERG, M. R.; NIELSEN, M. O. Effect of forage quality on intake, chewing 
activity, faecal particle size distribution, and digestibility of neutral detergent fibre in sheep, goats, and llamas. Small Ruminant Research, Arkansas, v.103, n.3, p.143-151, 2012.

LINHARES, P. C. F.; MARACAJA, P. B.; LIBERALINO FILHO, J.; VASCONCELOS, S. H. L.; NUNES, G. H. S. N. Inclusão de jitirana na composição químico- bromatológica de silagem de milho. Revista Caatinga, Mossoró, v.18, n.2, p.117-122, 2005.

LINHARES, P. C. F.; SILVA, D. L. S.; VASCONCELOS, S. H. L.; BRAGA, A. P.; MARACAJA, P. B. Teor de matéria seca e composição químico-bromatológica da jitirana (Merremia aegyptia L. Urban) em diferentes estádios fenológicos. Revista Verde de Agroecologia e Desenvolvimento Sustentável, Pombal, v.5, n.3, p.255-262, 2010.

MACEDO JÚNIOR, G. L.; PÉREZ, J. R. O.; ALMEIDA, T. R. V.; PAULA, O. J.; FRANÇA, P. M.; ASSIS, R. M. Influência de diferentes níveis de FDN dietético no consumo e digestibilidade aparente de ovelhas Santa Inês. Ciência e Agrotecnologia, Lavras, v.30, n.3, p.547-553, 2006.

MERTENS, D. R. Impact of NDF content and digestibility on dairy cow performance. WCDS Advances in Dairy Technology, v.21, p.191-201, 2009.

NATIONAL RESEARCH COUNCIL (NRC). Nutrient requirements of small ruminants: sheep, goats, cervids, and new world camelids. Washington, D.C.: National Academy Press, 2007. $362 \mathrm{p}$

PEEL, M. C.;FINLAYSON, B. L.; McMAHON, T. A. Updated world map of the Köppen-Geiger climate classification. Hydrology Earth System Sciences, Munique, v.11, p.1633-1644, 2007.

RESENDE, K. T.; SILVA, H. G. O.; LIMA, L. D.; TEIXEIRA, I. A. M. A. Avaliação das exigências nutricionais de pequenos ruminantes pelos sistemas de alimentação recentemente publicados. Revista Brasileira de Zootecnia, Viçosa-MG, v.37, p.161-177, 2008.

STATISTICAL ANALYSIS SYSTEM (SAS). SAS/STAT User's Guide. Cary, NC: SAS Institute, 2001. 